\title{
Elevated pigment epithelium-derived factor induces diabetic erectile dysfunction via interruption of the Akt/Hsp90ß/eNOS complex
}

\author{
Di Che ${ }^{1,2,3} \cdot$ Zhenzhen Fang ${ }^{2} \cdot$ Li Yan ${ }^{4}$ Jieping Du ${ }^{4} \cdot$ Fangping $\mathrm{Li}^{4} \cdot$ Jinye $\mathrm{Xie}^{2} \cdot$ Juan Feng ${ }^{2} \cdot$ Ping Yin $^{2} \cdot$ Weiwei $\mathbf{Q i}^{2}$. \\ Zhonghan Yang ${ }^{2}$. Jianxing $\mathrm{Ma}^{5} \cdot$ Xia Yang ${ }^{1,2,6}$. Guoquan Gao ${ }^{1,2,7} \cdot$ Ti Zhou $^{1,2}$
}

Received: 13 September 2019 / Accepted: 9 March 2020 / Published online: 6 May 2020

(C) Springer-Verlag GmbH Germany, part of Springer Nature 2020

\begin{abstract}
Aims/hypothesis Diabetes mellitus erectile dysfunction (DMED) is a common complication of diabetes. The level of pigment epithelium-derived factor (PEDF) is significantly upregulated in the serum of individuals with obesity and diabetes. However, whether elevated PEDF levels contribute to DMED remains unknown. This study aimed to investigate the pathogenic role of PEDF and its related mechanism in DMED.

Methods We enrolled 65 men, of whom 20 were nondiabetic control participants, 21 participants with diabetes but without erectile dysfunction, and 24 with DMED. The International Index of Erectile Function (IIEF-5) questionnaire was administered to evaluate erectile function. Plasma PEDF in diabetic participants and streptozotocin (STZ)-induced diabetic animals was detected by ELISA. Erectile function was evaluated by measuring the intracavernous pressure (ICP) and the ICP/mean arterial pressure (MAP) ratio in STZ-induced diabetic rats treated with PEDF-neutralising antibody (PEDF-Ab), $d b / d b$ mice treated with PEDF$\mathrm{Ab}$, and Pedf knockout mice with STZ-induced diabetes. The overexpression of PEDF was implemented by intraperitoneal injection of recombinant PEDF and intracavernous injection of $P E D F$-expressing adenovirus. A mechanistic study was performed by immunofluorescence staining, bimolecular fluorescence complementation (BiFC), immunoprecipitation and western blotting.

Results We found that the plasma level of PEDF was significantly higher in participants with DMED compared with diabetic counterparts without erectile dysfunction and nondiabetic controls. Interestingly, PEDF levels were negatively correlated with plasma nitrite/nitrate levels and erectile function in DMED patients and STZ-induced diabetic rats. Furthermore, overexpression of PEDF significantly suppressed ICP and endothelial nitric oxide synthase (eNOS) phosphorylation in control rats. In contrast, the PEDF-Ab and Pedf knockout ameliorated ICP and eNOS phosphorylation in diabetic rats and mice. Mechanistically, PEDF
\end{abstract}

Di Che and Zhenzhen Fang contributed equally to this study.

Electronic supplementary material The online version of this article (https://doi.org/10.1007/s00125-020-05147-y) contains peer-reviewed but unedited supplementary material, which is available to authorised users.

Ti Zhou

zhouti2@mail.sysu.edu.cn

$\bowtie$ Guoquan Gao

gaogq@mail.sysu.edu.cn

$\triangle \quad$ Xia Yang

yangxia@mail.sysu.edu.cn

1 Program of Molecular Medicine, Affiliated Guangzhou Women and Children's Hospital, Zhongshan School of Medicine, Sun Yat-sen University, Guangzhou, China

2 Department of Biochemistry, Zhongshan School of Medicine, Sun Yat-sen University, 74 Zhongshan Road II, Guangzhou 510080, China
3 Department of Clinical Biological Resource Bank, Guangzhou Institute of Pediatrics, Guangzhou Women and Children's Medical Center, Guangzhou, China

4 Department of Endocrinology, Second Affiliated Hospital, Sun Yat-sen University, Guangzhou, China

5 Department of Physiology, University of Oklahoma, Health Sciences Center, Oklahoma City, OK, USA

6 Guangdong Engineering \& Technology Research Center for Gene Manipulation and Biomacromolecular Products, Sun Yat-sen University, Guangzhou, China

7 Guangdong Province Key Laboratory of Brain Function and Disease, Zhongshan School of Medicine, Sun Yat-sen University, Guangzhou, China 


\section{Research in context}

\section{What is already known about this subject?}

- Cavernosal endothelial dysfunction is recognised as a hallmark of the pathology of diabetes mellitus erectile dysfunction (DMED)

- Levels of pigment epithelium-derived factor (PEDF) are significantly upregulated in the serum of individuals with obesity and diabetes

- $\quad$ PEDF, a well-known angiogenesis inhibitor, is a member of the serine protease inhibitor (Serpin) family. The mechanism by which PEDF inhibits angiogenesis is mainly attributed to inducing endothelial cell dysfunction or apoptosis in diabetic microvascular complications

What is the key question?

- Could PEDF play a key pathogenic role in DMED, and, if so, what is the underlying mechanism?

What are the new findings?

- We found that the plasma level of PEDF was significantly higher in participants with DMED compared with diabetic counterparts without erectile dysfunction and nondiabetic control participants. PEDF levels were negatively correlated with plasma nitrite/nitrate levels and erectile function in DMED patients and streptozotocin-induced diabetic rats

- $\quad$ PEDF overexpression significantly suppressed intracavernous pressure (ICP) and endothelial nitric oxide synthase (eNOS) phosphorylation in control rats. In contrast, PEDF-neutralising antibody and Pedf knockout ameliorated ICP and eNOS phosphorylation in diabetic rats and mice

- PEDF promoted the membrane translocation of $\mathrm{Hsp} 90 \mathrm{\beta}$ and directly bound to the amino acid residues 341-724 of Hsp90 $\beta$ on the cell surface, subsequently blocking intracellular Hsp90ß/Akt/eNOS complex formation and downregulating eNOS phosphorylation

\section{How might this impact on clinical practice in the foreseeable future?}

- The blockade of PEDF in the early stage of DMED represents a potential therapeutic target for the treatment of this condition

promoted the membrane translocation of Hsp90 $\beta$ and directly bound to the amino acid residues $341-724$ of Hsp90 $\beta$ on the endothelial cell surface, subsequently blocking intracellular Hsp90ß/Akt/eNOS complex formation and downregulating eNOS phosphorylation.

Conclusions/interpretation These results indicate that elevated PEDF levels contribute to impaired erectile function by suppressing Hsp90 3 -mediated eNOS phosphorylation and that PEDF may represent a novel therapeutic target for diabetic erectile dysfunction.

Keywords Diabetes mellitus erectile dysfunction DMED · Endothelial cells eNOS · Hsp90 3 PEDF · Pigment epithelium-derived factor

\section{Abbreviations}

Ad-PEDF Adenovirus overexpressing PEDF

ATGL

$\mathrm{BiFC}$

CCEC

DMED

eNOS

Hsp90 $\beta$

HUVEC

ICP

\section{Adipose triglyceride lipase}

Bimolecular fluorescence complementation

Corpus cavernosum endothelial cell

Diabetes mellitus erectile dysfunction

Endothelial nitric oxide synthase

Heat shock protein $\beta$

Human umbilical vein endothelial cells

Intracavernous pressure
IIEF-5 International Index of Erectile Function

iNOS Cytokine-inducible nitric oxide synthase

LR Laminin receptor

LRP6 LDL receptor-related protein 6

MAP Mean arterial pressure

nNOS Neuronal nitric oxide synthase

PDE5I Phosphodiesterase type 5 inhibitor

PECAM-1 Platelet endothelial cell adhesion molecule 1

PEDF Pigment epithelium-derived factor

PEDF-Ab PEDF-neutralising antibody 
PI3K Phosphoinositide 3-kinase

PTEN Phosphatase and tensin homologue

rPEDF Recombinant His-PEDF

STZ Streptozotocin

\section{Introduction}

Erectile dysfunction is defined as the incapacity to achieve or maintain a penile erection sufficient for successful sexual intercourse [1]. Normal erectile function requires the coordination of neurological, vascular endothelial and endocrine systems [2]. NO-dependent relaxation of the cavernosal smooth muscles causes compression of the subtunical small veins, thus occluding local venous return and initiating a normal erection [2]. Erectile dysfunction is classified as psychogenic, organic (neurogenic, hormonal, arterial or cavernosal) or mixed psychogenic and organic [3]. The risk factors associated with vasculogenic erectile dysfunction include diabetes mellitus, atherosclerosis, hypertension and hyperlipidaemia [4].

Diabetes is one of the most common chronic diseases worldwide. The number of cases is estimated to rise to 552 million by 2030 [5]. It has been reported that erectile dysfunction is a common complication in diabetes and occurs in 50$75 \%$ of men with diabetes worldwide [6]. The incidence of erectile dysfunction is three times as high in diabetic men as in nondiabetic men [7]. Furthermore, erectile dysfunction occurs at a younger age in men with diabetes than in the general population [8], and it usually arises within 10 years of diabetes onset [9]. Erectile dysfunction seriously decreases the quality of life in diabetic men and affects intimate relationships. Therefore, the study of diabetes mellitus erectile dysfunction (DMED) has attracted increasing attention.

The pathogenesis of DMED is complex and has not been fully elucidated. Among multiple factors, cavernosal endothelial dysfunction is recognised as a hallmark of the disease pathology [10]. The key feature of endothelial dysfunction is a reduction of the production and bioavailability of NO [11], leading to a decrease in vasodilation; it is usually caused by reduced synthesis and/or loss of endothelial nitric oxide synthase (eNOS) bioactivity and bioavailability in the vasculature [12]. Moreover, many studies have found that patients in the early stages of diabetes with erectile dysfunction suffer a widespread endothelial dysfunction, after which endothelial cells and smooth muscle cells begin to undergo apoptosis [13], the hard white elastic membrane protein accumulates, collagen is deposited, the basement membrane becomes thick and fibrosis increases.

Pigment epithelium-derived factor (PEDF), a wellknown angiogenesis inhibitor, is a member of the serine protease inhibitor (Serpin) family [14]. The mechanism by which PEDF inhibits angiogenesis is by targeting endothelial cells [15]. Others and our previous study found that PEDF levels are significantly upregulated in the serum of individuals with obesity, diabetes, and the metabolic syndrome compared with non-obese or nondiabetic people [16-18]. However, whether PEDF is a causative contributor in DMED is unknown. Therefore, the present study investigated the pathogenic role of PEDF in DMED and the underlying mechanism.

\section{Methods}

Human participants This study was conducted in accordance with the ethical principles derived from the Declaration of Helsinki and Belmont Report and was approved by the review board of Sun Yat-sen University (Guangzhou, China). We enrolled 65 men, of whom 20 were nondiabetic control participants, 21 participants with diabetes but without erectile dysfunction, and 24 with DMED; all of them were in stable marital relationships. All patients with diabetes were admitted to the Endocrinology Department of the Second Affiliated Hospital of Sun Yat-sen University, and all participants provided written informed consent. Diabetes was clinically diagnosed in accordance with the WHO standard. The diagnosis of erectile dysfunction was according to the International Index of Erectile Function (IIEF-5), and a score $\leq 21$ was considered to be erectile dysfunction. Exclusion criteria included being affected by the history of anatomic abnormalities of the penis (Peyronie's disease); previous gonadectomy or pelvic surgery; previous history of clinical neoplasm, organ transplantation, active liver disease or hypo- or hyperthyroidism; taking drugs for the treatment of erectile dysfunction; or being unable to give informed consent. All participants were randomly selected from the group that met the inclusion criteria. Blinding was not carried out for the human sample experiments.

Animals and treatments The Animal Care and use Committee of Sun Yat-sen University approved the experiments. Sprague Dawley rats and C57BL/6 mice were purchased from the Animal Center of Guangdong Province (Guangzhou, China). Pedf homozygous $\mathrm{KO}\left(\mathrm{Pedf}^{--}\right)$mice were provided by S. J. Wiegand (Regeneron Pharmaceuticals, Tarrytown, NY, USA). Sprague Dawley rats, C57BL/6 mice and Pedf homozygous $\mathrm{KO}\left(\mathrm{Ped} \mathrm{f}^{--}\right)$mice were randomly divided into two groups, respectively, one group as a control and the other as a diabetic model. Diabetes was induced in 8-week-old mice by intraperitoneal injections of streptozotocin (STZ; $50 \mathrm{mg} / \mathrm{kg}$ ) consecutively for 5 days, and diabetes was induced in 8-weekold rats by intraperitoneal injections of STZ $(50 \mathrm{mg} / \mathrm{kg})$, as previously described in the literature [19]. B6.BKS(D)- 
Leprdb/Nju $(d b / d b)$ mice were purchased from the Model Animal Research Center of Nanjing University. All animals were kept in a specific pathogen-free environment in this study. Apomorphine (APO, $100 \mathrm{mg} / \mathrm{kg}$ ) (Sigma, USA) was used to identify the rats with erectile dysfunction from among the diabetic rats according to Heaton's method and as previously reported [20]. Rats that did not receive an erectile response to APO after subcutaneous injection were considered to have developed erectile dysfunction. PEDF-neutralising antibody (PEDF-Ab) and recombinant His-PEDF protein (rPEDF) were obtained as previously described [21]. Sprague Dawley rats were injected intraperitoneally with rPEDF $(2.5 \mathrm{mg} / \mathrm{kg}$ ) daily for 4 weeks, and the control group was injected with the same concentration of BSA (Sigma). For neutralising PEDF, diabetic rats or $d b / d b$ mice were injected intraperitoneally with PEDF-Ab (GenScript) $0.4 \mathrm{mg} / \mathrm{kg}$ per day for 2 weeks, and the control group was injected with the same concentration of nonspecific IgG (Sigma) as previously described [16]. Adenovirus overexpressing PEDF (Ad$P E D F$ ) was constructed using full-length human $P E D F$ cDNA as previously described [22], and adenovirus overexpressing green fluorescent protein (Ad-gfp) was used as the control virus. The viruses were injected into the rat corpus cavernosum $\left(5 \times 10^{8}\right.$ virus particles $[\mathrm{vp}] / 20 \mu \mathrm{l}$ per week for 4 weeks) as previously described [23]. Blinding was not carried out for the animal experiments.

Measurement of erectile function Erectile function was assessed by electrical stimulation of the cavernous nerve. Stimulation parameters were $5 \mathrm{~V}$ at a frequency of $12 \mathrm{~Hz}$, a pulse width of $1 \mathrm{~ms}$, and a duration of $1 \mathrm{~min}$. The ratios of maximal intracavernous pressure (ICP) and total ICP (reported as AUC) to mean arterial pressure (MAP) were calculated to adjust for variations in systemic blood pressure, as previously described [24].

Cell culture experiments Rat corpus cavernosum endothelial cells (CCECs) were purchased from Procell Life Science \& Technology. HUVECs were isolated from the human umbilical cord as previously described [25]. The cells were cultured on $0.2 \%$ gelatine (Sigma) culture flasks in endothelial cell medium (ECM; ScienCell, USA) with 10\% FBS, $100 \mu \mathrm{g} / \mathrm{ml}$ of streptomycin and $100 \mu \mathrm{g} / \mathrm{ml}$ of penicillin. The cells used in the experiment underwent 2-5 passages. All cells were incubated in a humidified atmosphere at $37^{\circ} \mathrm{C}$ with $5 \% \mathrm{CO}_{2}$. The phenotype analysis was performed with immunofluorescence staining with anti- PECAM-1 antibody. Cell lines have no mycoplasma contamination.

Western blot and histological examinations Membrane-cytoplasmic fractionation was performed using a Plasma Membrane Protein Isolation Kit (Invent Biotechnologies, USA). Western blot analysis and histological examinations were performed as described previously [26]. Antibody information is detailed in ESM Table 1. The results were quantified by the National Institutes of Health [NIH] ImageJ 1.34 (USA).

ELISA specific for NO/PEDF The concentrations of PEDF in human and rat plasma were quantified by commercial ELISA kits purchased from R\&D Systems (USA) and Sangon Biotech (China), respectively. NO concentration in endothelial cells was determined using commercial kits purchased from Beyotime (China). Nitrite/nitrate concentrations in plasma were determined using commercial kits purchased from R\&D Systems. Because NO in biological fluids has a short half-life, the levels of the more stable NO metabolites, nitrite/ nitrate, are used to indicate the NO concentration in plasma.

Expression vector construction Human full-length $A K T$ (also known as $A K T 1$ ), $P E D F, H S P 90 B$ and $e N O S$ (also known as $N O S 3$ ) cDNAs were generated by RT-PCR. Several HSP90B truncates were generated by PCR and subcloned into a pCDNA3.1-3 $\times$ HA-N vector purchased from Wuhan Miaoling Bioscience \& Technology (P0160). Plasmids encoding $H S P 90 B$ and $A K T$ were fused to the $\mathrm{N}$-terminal fragment of Venus (VN155-I152 L, AKT-VN, HSP90B-VN), and $A K T$, $e N O S$ and $P E D F$ were fused to the C-terminal fragment of Venus (VC155, AKT-VC, eNOS-VC, PEDF-VC) as previously described [27], VN155-I152 L and VC155 were a gift from C. Hu (Purdue University).

Bimolecular fluorescence complementation For bimolecular fluorescence complementation (BiFC) experiments, 293T cells (purchased from the Chinese Academy of Sciences) were co-transfected with $e N O S$-VC and $A K T$ $\mathrm{VN}, H S P 90 B-\mathrm{VN}$ and $A K T-\mathrm{VC}, H S P 90 B-\mathrm{VN}$ and eNOS-VC, or $H S P 90 B-\mathrm{VN}$ and $P E D F-\mathrm{VC}$ plasmids, respectively, for $24 \mathrm{~h}$ and then visualised under a fluorescence microscope (Axio Observer Z1, Zeiss, Germany). Only when they were in close proximity do the two Venus half-sites complement each other and form a functional Venus. The fluorescent signals were quantitatively analysed with NIH ImageJ 1.34, which indicated binding between eNOS and Akt, Hsp90 $\beta$ and Akt, Hsp90 $\beta$ and eNOS or Hsp90 $\beta$ and PEDF.

Biotinylation of cell surface proteins The assay that involved analysis of the cell surface expression of Hsp $90 \beta$ was used as previously described [28]. First, cell surface proteins were labelled with biotin using Sulfo-NHS-LC-Biotin (ThermoFisher, USA) according to the manufacturer's instructions. Cells were extracted using RIPA lysis buffer as indicated previously, and antibodies against Hsp90 $\beta$ were incubated with cell lysates overnight. 


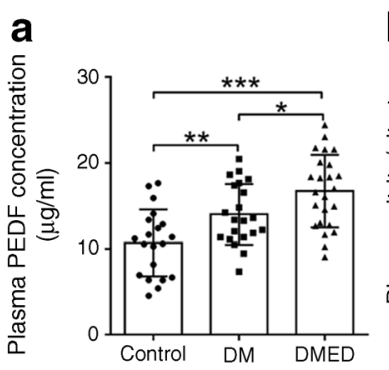

b

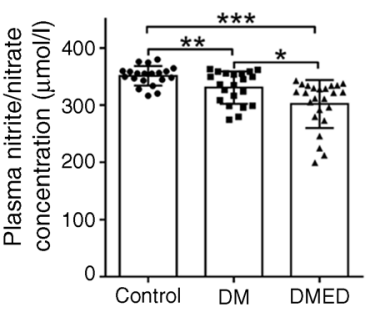

f
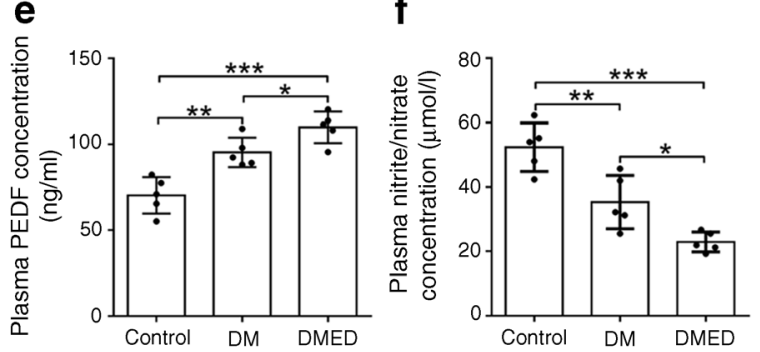

Fig. 1 Elevated plasma PEDF is negatively correlated with nitrite/nitrate concentration and erectile function in participants with DMED and in animal models. (a, b) plasma PEDF (a) and nitrite/nitrate (b) concentration (control $n=20$; DM, diabetic participants without DMED, $n=21$; DMED, $n=24)$. (c, d) Correlation analysis of plasma PEDF levels with nitrite/nitrate levels and IIEF-5 scores. Black, control; blue, DM; red,

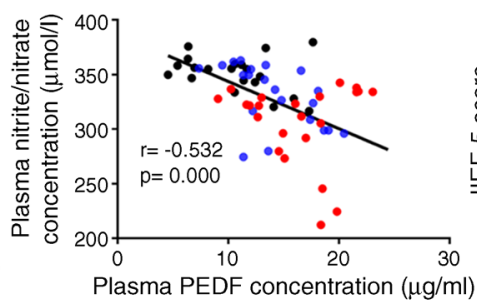

g

d

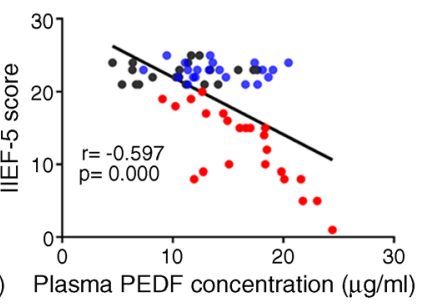

h
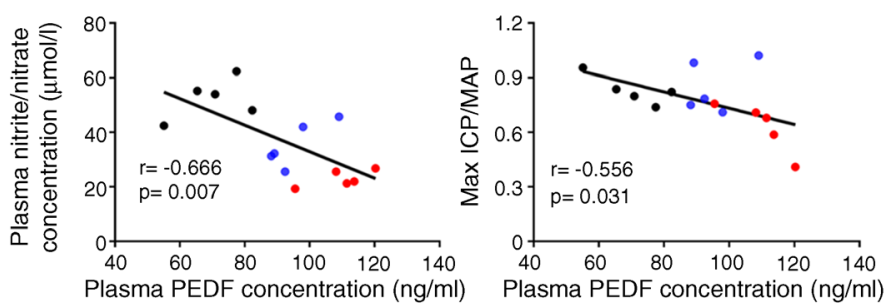

DMED. (e, f) Plasma PEDF (e) and plasma nitrite/nitrate (f) concentrations in STZ-induced diabetic Sprague Dawley rats with or without erectile dysfunction $(n=5)$. (g, h) Correlation analysis of plasma PEDF levels with nitrite/nitrate levels and maximal (Max) ICP/MAP in diabetic rats. Black, control; blue, DM; red, DMED. Bars correspond to the mean \pm SD. $* p<0.05, * * p<0.01, * * * p<0.001$
Fig. 2 High levels of PEDF contribute to suppressing erectile function in Sprague Dawley rats. (a, d) Representative ICP of Sprague Dawley rats following (a) rPEDF intraperitoneal injection and (d) Ad- $P E D F$ cavernous injection. (b, c, e, f) Quantification of ratios of maximal (Max) ICP to MAP and ratios of total ICP (AUC) to MAP in the rPEDF intraperitoneal injection group $(\mathbf{b}, \mathbf{c})$ and the Ad$P E D F$ cavernous injection group $(\mathbf{e}, \mathbf{f})$. Controls are untreated rats (blank) and rats treated with BSA $(\mathbf{a}-\mathbf{c})$ or Ad- $g f p(\mathbf{d}-\mathbf{f})$. Bars correspond to the mean $\pm \mathrm{SD}$ from $n=5$ animals per group. $* p<0.05, * * p<0.01$, $* * * p<0.001$ a
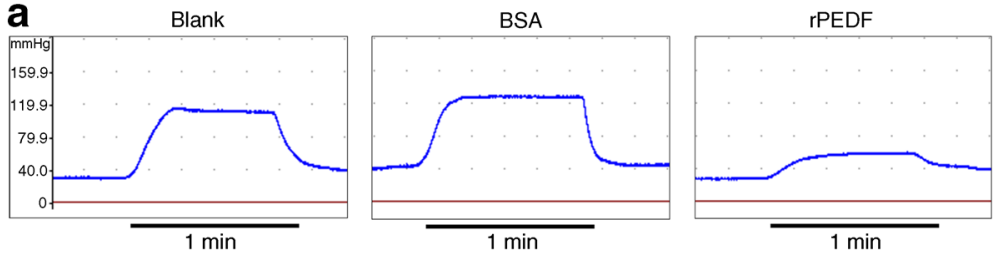

b
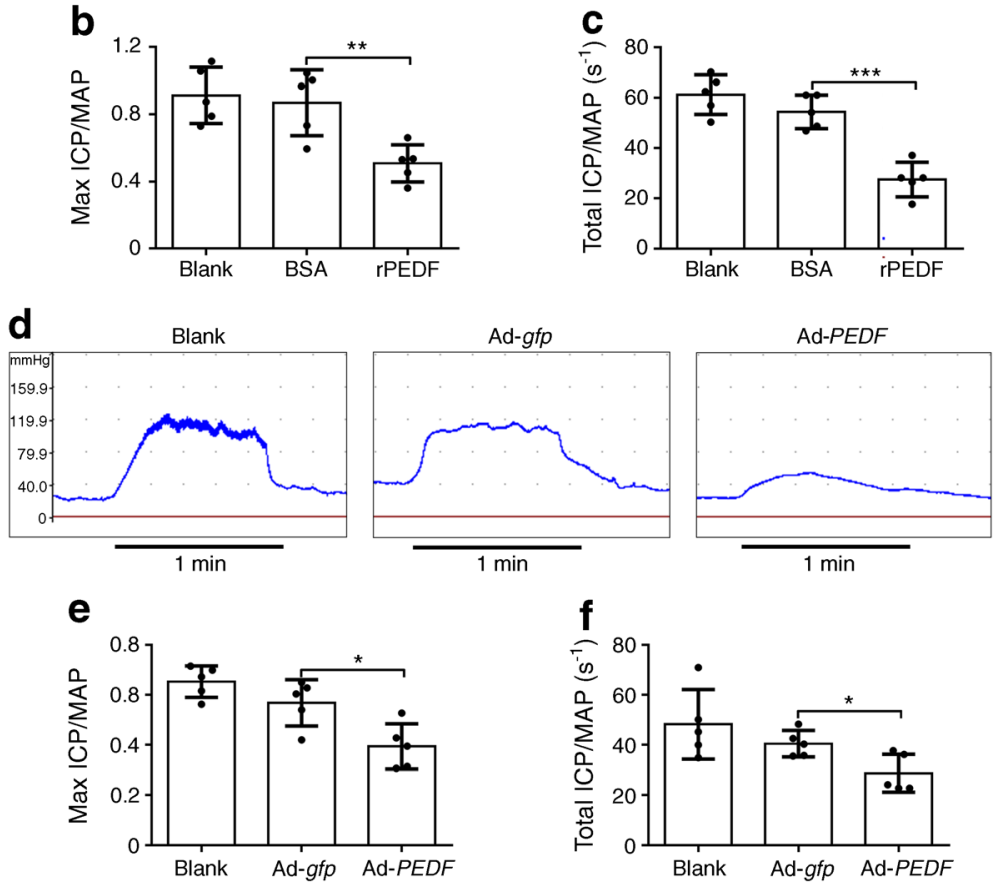
Finally, Western blotting for streptavidin (CST) was used to detect cell surface biotin-conjugated Hsp90ß.

Statistical analysis The results are reported as mean $\pm \mathrm{SD}$. Intergroup comparisons of parametric data were made using Student's $t$ test or one-way ANOVA followed by the Newman-Keuls post hoc test. We used the MannWhitney rank sum or Kruskal-Wallis test to compare nonparametric data. We performed statistical analysis with SPSS.20 (IBM, USA) for statistical analyses. All $p$ values were two-sided, and $p<0.05$ was considered statistically significant.

\section{Results}

Elevated plasma PEDF is negatively correlated with nitrite/ nitrate concentration and erectile function in participants with DMED and animal models The clinical characteristics and laboratory variables of the three groups are presented in ESM Table 2. As expected, participants with DMED had significantly lower IIEF-5 scores than nondiabetic control participants and diabetic participants without DMED (ESM Table 2). The plasma level of PEDF was significantly higher in DMED patients $(16.72 \pm 4.22 \mu \mathrm{g} / \mathrm{ml}, n=24)$ compared with the diabetic individuals without DMED (14.02 \pm
Fig. 3 PEDF neutralisation antibody and PEDF deficiency ameliorate erectile function in diabetic rats and mice with DMED, respectively. $(\mathbf{a}-\mathbf{c})$ Representative ICP and quantification of ratios of maximal (Max) ICP to MAP and ratios of total ICP (AUC) to MAP in diabetic rats after 8 weeks of STZ-induced diabetes, treated with IgG or PEDF-Ab. (d-f) Representative ICP and quantification of ratios of Max ICP to MAP and ratios of total ICP to MAP in 12-week-old $d b /$ $d b$ mice treated with IgG or PEDF-Ab. (g-i) Representative ICP and quantification of ratios of Max ICP to MAP and ratios of total ICP to MAP in Pedf $f^{--}$mice and wild-type (control) mice after 8 weeks of STZ-induced diabetes. Bars correspond to the mean \pm SD from $n=5$ animals per group. $* p<0.05, * * p<0.01$, $* * * p<0.001$
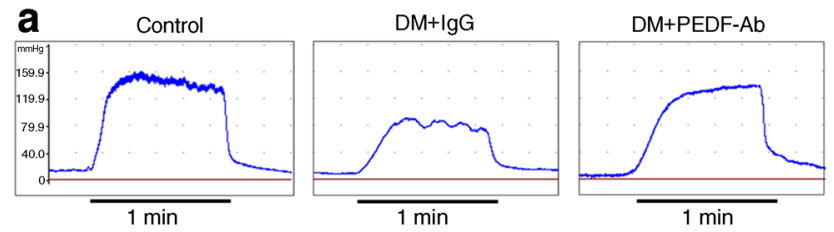

\section{b}

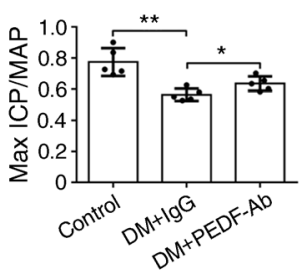

c
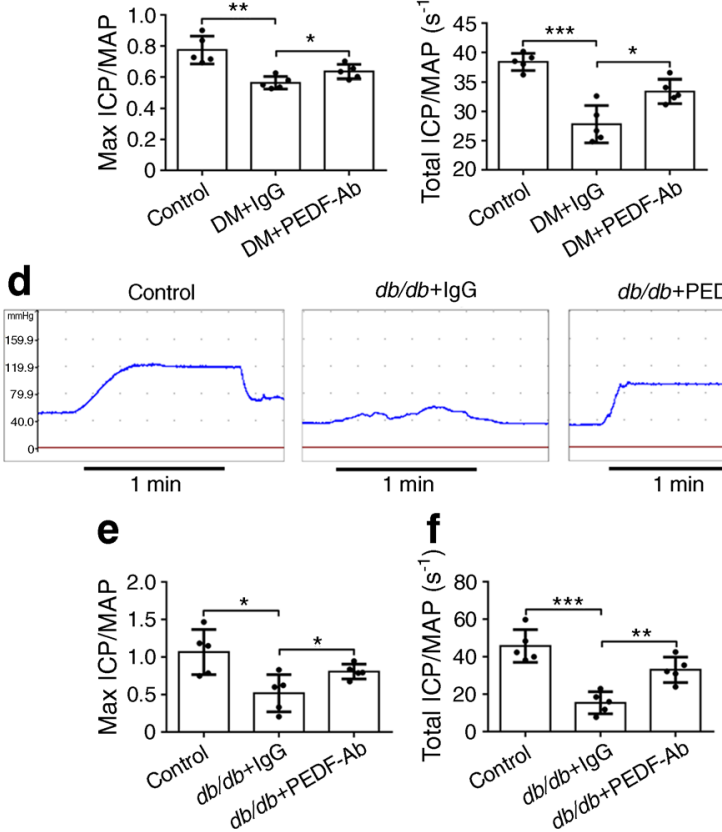

$d b / d b+\lg G$

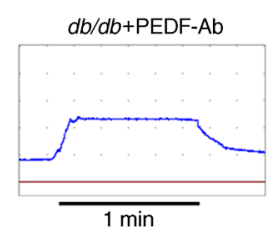

e
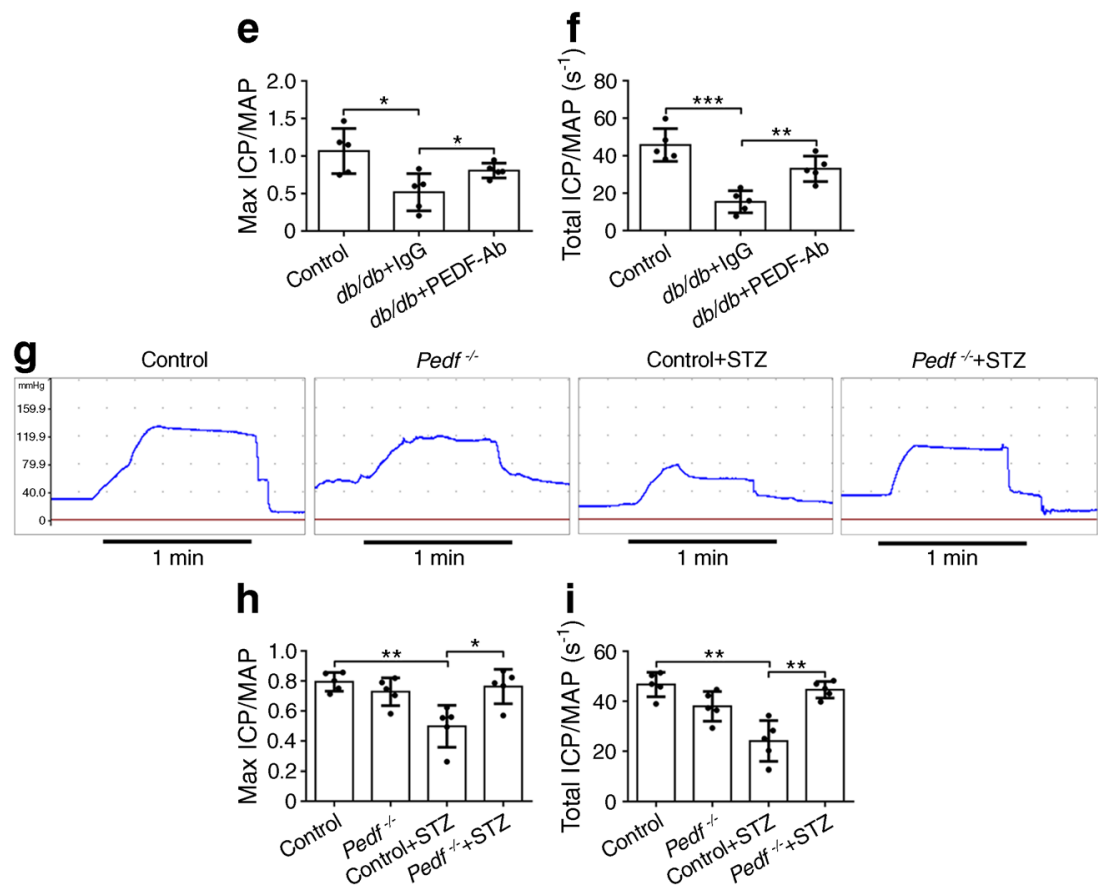
$3.54 \mu \mathrm{g} / \mathrm{ml}, p=0.011, n=21)$ and nondiabetic control participants $(10.69 \pm 3.89 \mu \mathrm{g} / \mathrm{ml}, p=0.000, n=20)$ (Fig. 1a). In contrast, DMED patients showed decreased plasma nitrite/ nitrate levels compared with diabetic patients without DMED and control participants $(301.91 \pm 42.02 \mu \mathrm{mol} / 1 \mathrm{vs}$ $330.79 \pm 28.39 \mu \mathrm{mol} / 1, p=0.013$ and vs $351.30 \pm$ $17.10 \mu \mathrm{mol} / \mathrm{l}, p=0.000$ ) (Fig. 1b). Next, we analysed the relation between PEDF and nitrite/nitrate content as well as IIEF-5 scores. PEDF levels were negatively correlated with nitrite/nitrate $(r=-0.532, p=0.000)$ (Fig. 1c) and IIEF-5 scores $(r=-0.597, p=0.000)$ (Fig. 1d). Furthermore, we demonstrated that elevated PEDF levels were involved in
DMED animal models. Similarly to the data in human participants, it showed that PEDF levels in rats with DMED were higher than in diabetic rats without DMED and control rats $(109.82 \pm 9.14 \mathrm{ng} / \mathrm{ml}$ vs $95.34 \pm 8.56 \mathrm{ng} / \mathrm{ml}, p=0.032$ and vs $70.23 \pm 10.62 \mathrm{ng} / \mathrm{ml}, p=0.000$ ) (Fig. 1e). The nitrite/nitrate content exhibited the opposite tendency (DMED 23.30 \pm $2.97 \mu \mathrm{mol} / 1$ vs diabetic without DMED $35.32 \pm 8.30 \mu \mathrm{mol} / \mathrm{l}$, $p=0.009$; vs control $52.40 \pm 7.53 \mu \mathrm{mol} / \mathrm{l}, p=0.000$ ) (Fig. 1f). The PEDF level was consistently negatively correlated with nitrite/nitrate $(r=-0.666, p=0.007)$ (Fig. $1 \mathrm{~g})$ and maximal ICP/MAP $(r=-0.556, p=0.031)$ (Fig. 1h). These data suggest that elevated PEDF levels are involved in decreased
Fig. 4 PEDF suppressed eNOS phosphorylation levels in rats and mice with DMED. (a, b) p-eNOS (Ser ${ }^{1177}$; green) and PECAM-1 (red) immunostaining in penis tissue from age-matched control and diabetic rats after 6 weeks of STZ-induced diabetes. (c, d) Representative immunoblot and quantification of $\mathrm{p}$-eNOS $\left(\mathrm{Ser}^{1177}\right)$ in penis tissue of $(\mathbf{c})$ Sprague Dawley rats with Ad$P E D F$ intracavernous injection and (d) 8 weeks of diabetes, treated with IgG or PEDF-Ab. (e, f) p-eNOS $\left(\mathrm{Ser}^{1177}\right.$; red) and PECAM-1 (green) immunostaining in penis tissue from Pedf $f^{-1}$ mice and wild-type (control) mice after 8 weeks of STZ-induced diabetes. Bars correspond to the mean $\pm \mathrm{SD}$, and experiments were replicated with three or more separate animals. Scale bars, $100 \mu \mathrm{m}$. * $p<0.05$, $* * p<0.01$
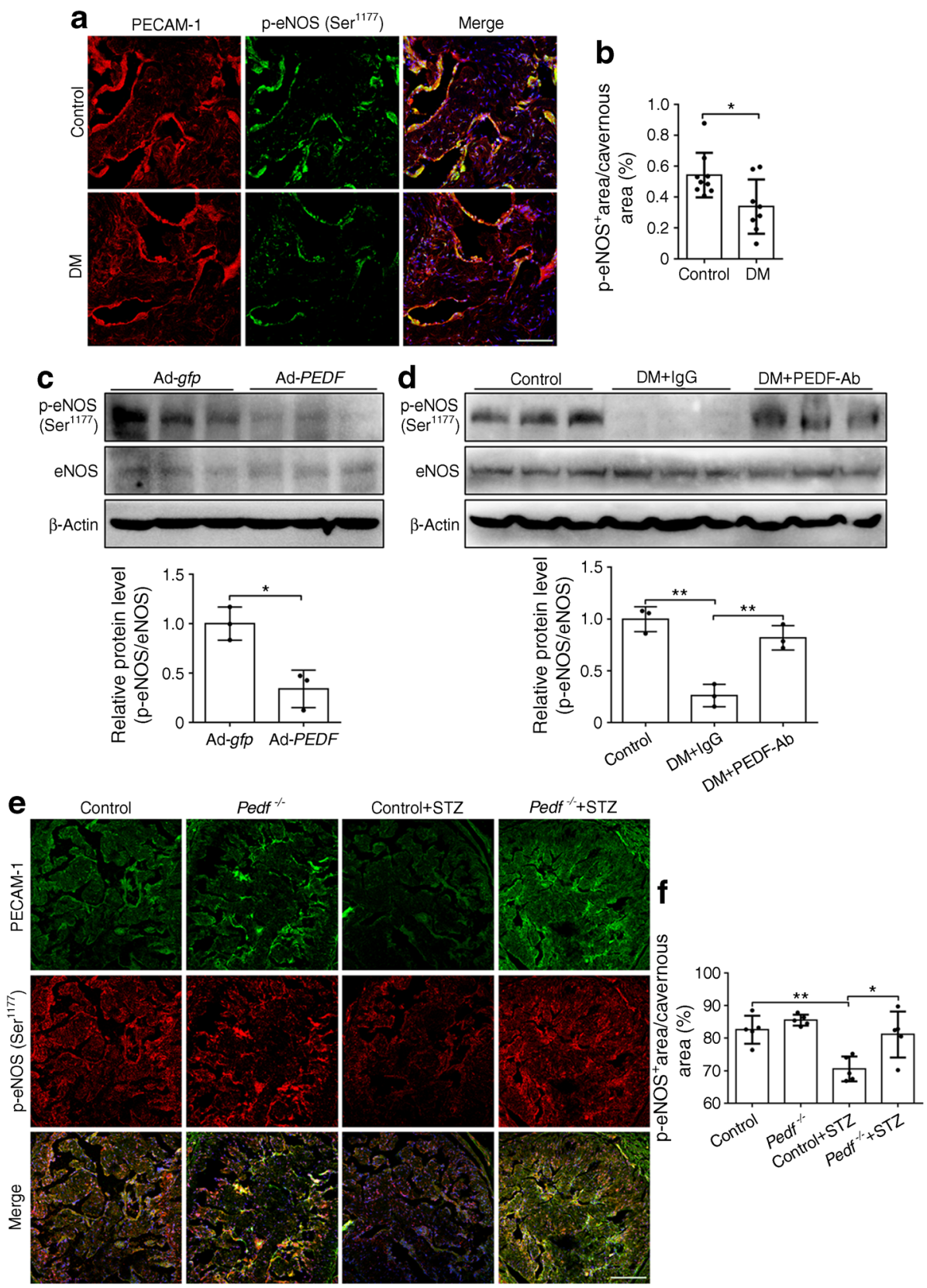
nitrite/nitrate levels and subsequent erectile dysfunction in DMED.

Overexpression of PEDF impairs erectile function in wild-type Sprague Dawley rats To verify the causative role of PEDF in erectile function, we examined the effect of exogenous PEDF administration on erectile function in nondiabetic control rats. After intraperitoneal injection of rPEDF, plasma PEDF levels were elevated as much as those in diabetic rats, and the corpus cavernosum PEDF levels were also increased in the intracavernous injected rats compared with controls (ESM Fig. 1). Figure 2a,d shows representative intracavernous tracing after stimulation of the cavernous nerve for $1 \mathrm{~min}$ in agematched ( \pm 3 days) untreated (blank) group, control group, and treated rats. The ratios of maximal ICP and total ICP to MAP were significantly lower in rPEDF- and Ad- $P E D F$-treated rats than in age-matched control groups (Fig. 2b,c and $2 \mathrm{e}, \mathrm{f})$. These data provide evidence that elevated PEDF plays a pathogenic role in impaired erectile function.

Blockage of PEDF ameliorates erectile function in diabetic rats and mice with erectile dysfunction To elucidate the contribution of PEDF in DMED, PEDF-Ab was used to block endogenous PEDF in diabetic rats, and $P e d f^{-1}$ diabetic mice were bred. The physiological and metabolic variables of diabetic animals are shown in ESM Tables 3-8 (there were significant differences in body weight, fasting glucose and postprandial glucose, but no difference in MAP, between the control and treated groups). Compared with IgG, PEDF-Ab improved the ratios of maximal ICP and total ICP to MAP in STZ-induced diabetic rats for 8 weeks (Fig. 3a-c) or 12 weeks (ESM Fig. $2 \mathrm{a})$ and 12 -week-old $d b / d b$ mice (Fig. 3d-f). Furthermore, the ratios of maximal ICP and total ICP to MAP were decreased in STZ-induced diabetes of type (control) mice, while ICP was restored in STZ-induced diabetes of Pedf $f^{-1}$ mice (Fig. $3 \mathrm{~g}$-i, ESM Fig. 2b,c). There was no difference in ICP in wildtype mice and $P e d f^{-1}$ mice without diabetes. These loss-offunction experiments indicate that a high level of PEDF contributes to erectile dysfunction.

PEDF suppresses eNOS phosphorylation in CCECs of animals with erectile dysfunction Cavernosal endothelial dysfunction is recognised as a hallmark of the disease pathology. We assumed that PEDF impaired erectile function by targeting CCECs. As shown in ESM Fig. 3, alterations in PEDF levels and erectile dysfunction occurred in STZ-induced diabetic rats after 6 weeks. Immunofluorescence staining with p-eNOS $\left(\operatorname{Ser}^{1177}\right) /$ platelet endothelial cell adhesion molecule 1
Fig. 5 PEDF suppresses eNOS phosphorylation levels and NO levels through the Akt signalling pathway in CCECs. $(\mathbf{a}, \mathbf{b}) \mathrm{p}$ eNOS $\left(\mathrm{Ser}^{1177}\right)$ and eNOS levels, and $(\mathbf{c}, \mathbf{d}) \mathrm{NO}$ concentration in CCECs treated with Ad-PEDF for $12 \mathrm{~h}$ or rPEDF for $60 \mathrm{~min}$. (e) p-eNOS $\left(\operatorname{Ser}^{1177}\right)$ and eNOS levels, and (f, g) NO concentration in CCECs treated with PEDF-Ab for 30 min and then exposed to $30 \mathrm{mmol} / \mathrm{l} \mathrm{D}$ glucose (HG) and L-glucose (LG) as a control for $6 \mathrm{~h}$. (h) p-eNOS $\left(\mathrm{Ser}^{1177}\right)$ and p-Akt $\left(\mathrm{Thr}^{308}\right)$ levels in CCECs treated with the Akt signalling agonist insulin $(100 \mathrm{nmol} / \mathrm{l})$ for $30 \mathrm{~min}$ and then exposed to rPEDF for $60 \mathrm{~min}$. Bars correspond to the mean \pm $\mathrm{SD}$, and experiments were replicated with three or more separate CCEC samples. $* p<0.05, * * p<0.01$, $* * * p<0.001$
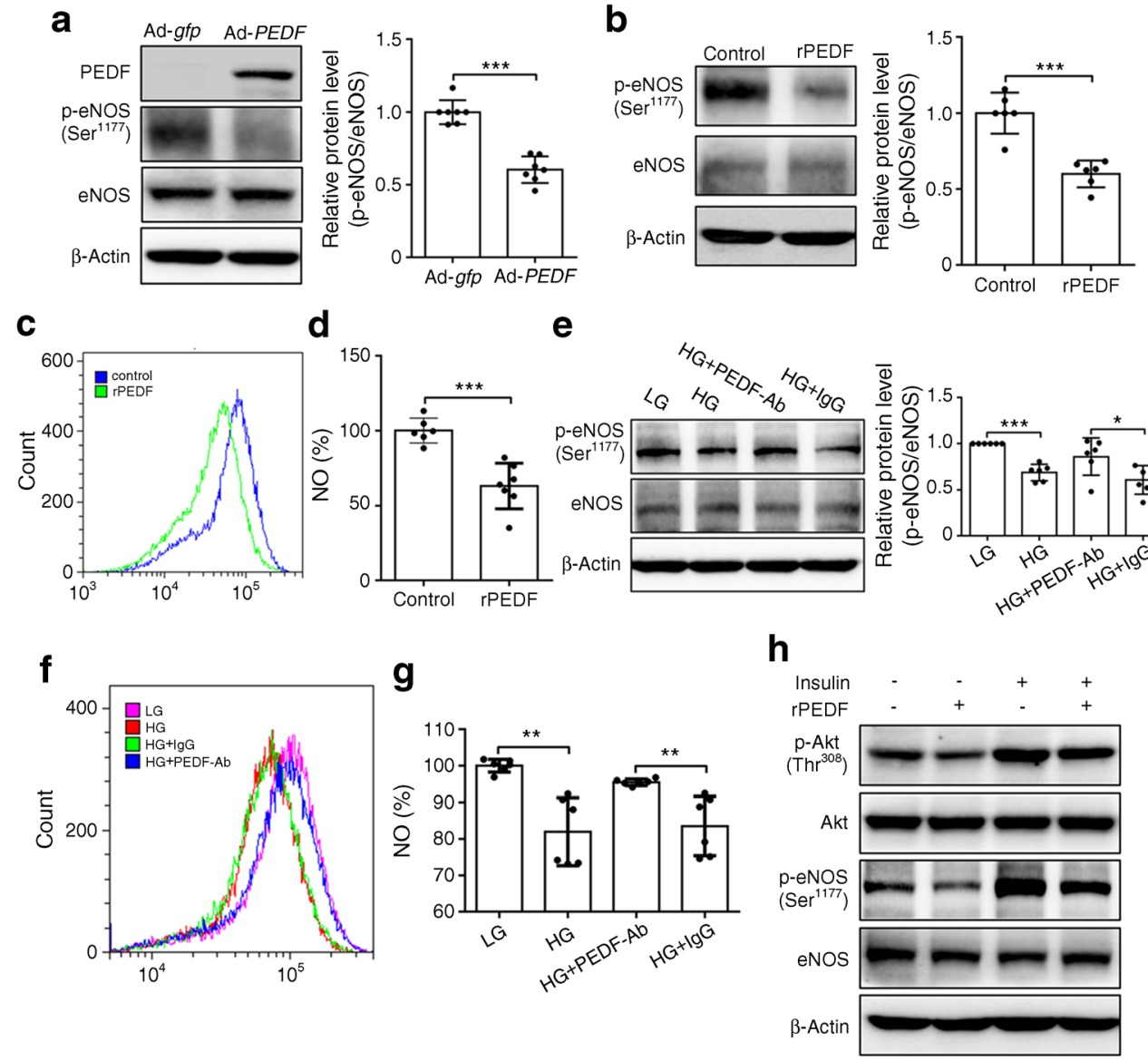
Fig. 6 PEDF interferes with the eNOS/Hsp90ß/Akt complex by binding to Hsp90ß. (a) Immunoprecipitation (IP) for PEDF in HUVECs treated with $30 \mathrm{mmol} / \mathrm{l} \mathrm{D}$-glucose (HG) and Lglucose (LG) as a control for $6 \mathrm{~h}$ (b) Co-immunoprecipitation blot and (c) quantification of endogenous eNOS, Akt, Hsp90ß and PEDF in HUVECs treated with Ad-PEDF. (d, e) BiFC assay with $e N O S$-VC and $A K T-\mathrm{VN}$, $H S P 90 B-\mathrm{VN}$ and $A K T-\mathrm{VC}$ or $H S P 90 B-\mathrm{VN}$ and $e N O S$-VC in $293 \mathrm{~T}$ cells. Images were acquired under a fluorescence microscope (scale bar, $200 \mu \mathrm{m}$ ). (f, g) BiFC (f) and co-immunoprecipitation (g) assays of Hsp90 $\beta$ and PEDF in 293T cells co-transfected with myc-tagged $H S P 90 B$-VN and $P E D F$-VC plasmids. Images were acquired under a fluorescence microscope (scale bar, $100 \mu \mathrm{m}$ ). Bars correspond to the mean $\pm \mathrm{SD}$, and experiments were replicated with three or more separate HUVEC or $293 \mathrm{~T}$ cell samples. $* * p<0.01$, $* * * p<0.001$. Ctrl, control
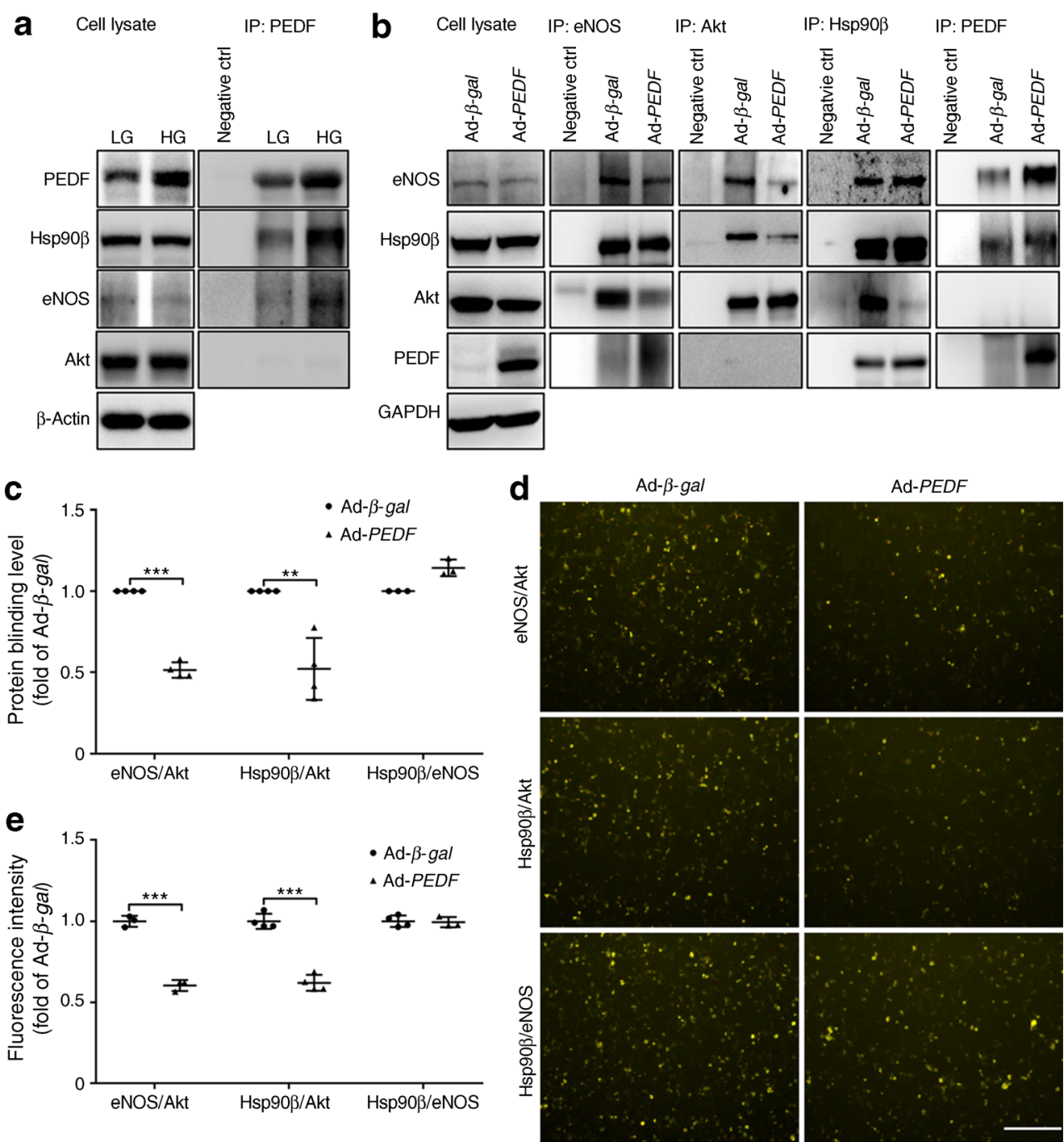

f

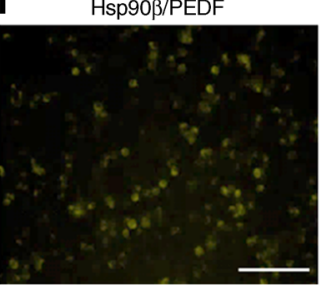

g

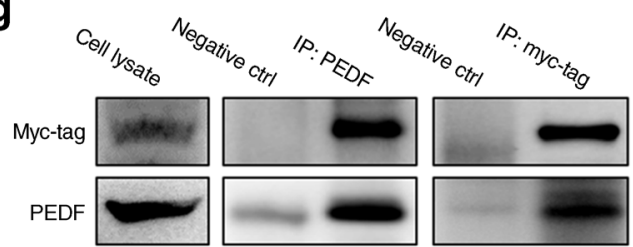

(PECAM-1) shows that the p-eNOS level was reduced 6 weeks after diabetes induction when no apoptosis was evident (Fig. 4a,b), and apoptosis occurred at 8 weeks after diabetes induction, suggesting that the decrease in eNOS phosphorylation preceded CCEC apoptosis (ESM Fig. 4). Consistently, Ad-PEDF intracavernous injection decreased the p-eNOS level in the wild-type rats (Fig. 4c), and similar results were obtained following exogenous rPEDF administration (ESM Fig. 5). Mechanistically, PEDF-Ab increases endothelial eNOS phosphorylation levels and nitrite/nitrate concentrations in diabetic animals during the early course of the disease, 8 weeks after diabetes-induction (Fig. $4 \mathrm{~d}$ and ESM Fig. 6a) and at 12 weeks (ESM Fig. 6b,c), whereas it was ineffective at a late stage, 16 weeks after diabetesinduction (data not shown). Correspondingly, we found that the p-eNOS level was remedied in $d b / d b$ mice with PEDF-Ab (ESM Fig. 6d) and Pedf ${ }^{-1}$ diabetic mice (Fig. 4e,f and ESM Fig. 7a,b).

PEDF reduces eNOS phosphorylation level through suppressing Akt signalling pathway activation in CCECs The preceding experiments showed that PEDF inhibited eNOS phosphorylation in animal models. In vitro, PEDF levels were increased, while p-Akt and p-eNOS levels were impaired in high glucose-treated CCECs (ESM Fig. 8a,b). Furthermore, rPEDF and Ad-PEDF both significantly decreased eNOS 
Fig. 7 PEDF inhibits Akt/eNOS signalling by decreasing the dimerisation of Hsp90 $\beta$ with direct binding to amino acid residues 341-724 of Hsp90ß. (a) The structural domains of the Hsp90 $\beta$ mutants used in these experiments are represented as black bars. The predicted binding site in $\mathrm{Hsp} 90 \beta$ is indicated by diagonal stripes. (b) Coimmunoprecipitation (IP) of PEDF and Hsp90 $\beta$ domains in 293T cells transfected with HAtagged Hsp90 $\beta$ constructs. (c) Native PAGE electrophoresis detected monomers $(90 \mathrm{kDa})$ and dimers $(180 \mathrm{kDa})$ of $\mathrm{Hsp} 90 \beta$ in HUVECs treated with $\mathrm{rPEDF}$ for $60 \mathrm{~min}$ or Ad-PEDF for $12 \mathrm{~h}$. (d) A speculative schematic of the interaction between PEDF and the eNOS complex. Experiments were replicated with three or more separate HUVEC or 293T cell samples. Ctrl, control

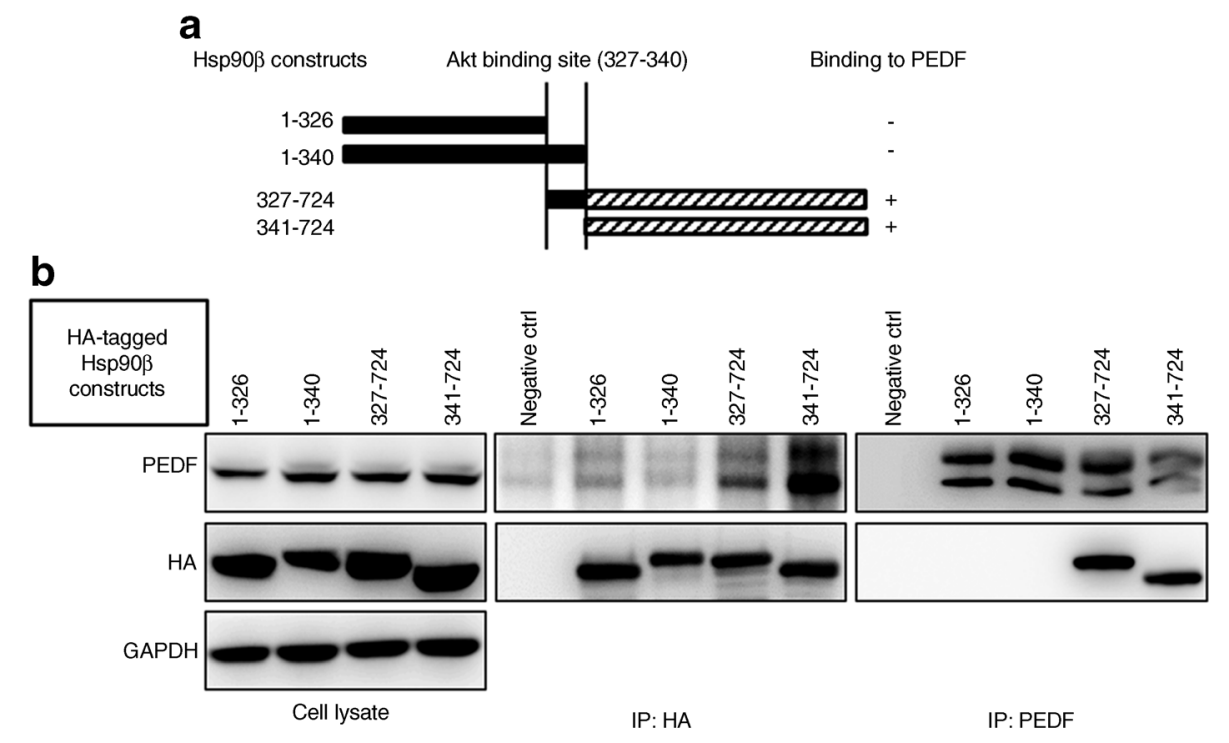

c
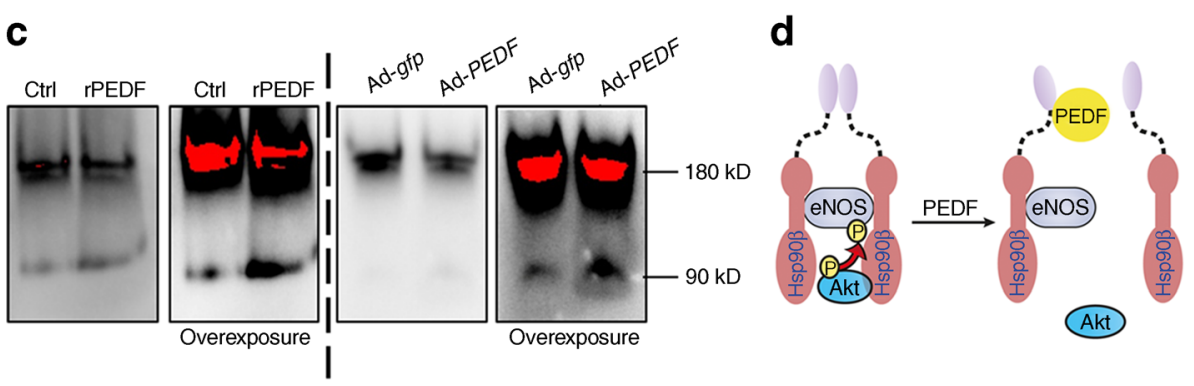

phosphorylation and subsequent NO synthesis in CCECs (Fig. 5a-d). In contrast, PEDF-Ab can restore the level of peNOS and NO decreased by high glucose in CCECs (Fig. 5eg). A contrary finding has shown that PEDF inhibits AGEBSA-induced phosphoinositide 3-kinase (PI3K)/Akt signalling in retinal endothelial cells [29], while PEDF protects pericyte cell death via activating the PI3K/Akt pathway [30]. Next, our mechanistic study indicated that PEDF inhibited Akt phosphorylation in endothelial cells, while AMPactivated protein kinase (AMPK) phosphorylation levels were unchanged (ESM Fig. 8c). Moreover, PEDF impaired the eNOS phosphorylation levels induced by insulin as an Akt agonist (Fig. 5h), and similar results were obtained in HUVECs (ESM Fig. 9). In vivo, reduced levels of p-Akt and $\mathrm{p}$-eNOS in the cavernous tissue were also observed in Ad-PEDF-treated rats (ESM Fig. 10a), and PEDF-Ab effectively rescued p-Akt and p-eNOS levels in the cavernous tissue of DM rats (ESM Fig. 10b). These results together suggest that PEDF decreases eNOS phosphorylation levels by suppressing Akt signalling pathway activation.

\section{PEDF inhibits Akt/eNOS signalling by decreasing the} dimerisation of $\mathrm{Hsp} 90 \mathrm{\beta}$ with direct binding to amino acid residues 341-724 of Hsp90 $\beta$ The following question arose about how PEDF inactivates Akt. We traced PI3K, which is upstream of Akt signalling, and phosphatase and tensin homologue (PTEN), an Akt suppressor in PEDF-treated cells. The phosphorylation levels of various subunits of PI3K and PTEN were unchanged by PEDF treatment in endothelial cells (ESM Fig. 11). These negative data indicate that PEDF might directly interact with Akt to suppress eNOS phosphorylation. The phosphorylation of eNOS is a complex process, and the binding of Hsp90 $\beta$ and eNOS facilitates the phosphorylation of eNOS by Akt. Thus, we explored the specific molecular mechanism by which PEDF downregulates eNOS phosphorylation by interfering with this complex. First, we found the binding of PEDF with the Hsp90ß/eNOS complex was increased in high glucose treatment (Fig. 6a). Next, we studied the direct effect of PEDF on the interaction of this complex. Co-immunoprecipitation experiments showed that PEDF reduced the binding of Akt/eNOS and Hsp90ß/Akt, but had no effect on the binding of Hsp90 $\beta$ and eNOS, and PEDF had no interaction with Akt (Fig. 6b,c). Consistently, BiFC showed similar results (Fig. 6d,e). These data prompt us to conclude that the binding of PEDF to Hsp90 $\beta$ abolished the $\mathrm{Akt} / \mathrm{Hsp} 90 \mathrm{\beta}$ interaction. This was also supported by the BiFC and immunoprecipitation experiments, which showed that PEDF could directly bind with Hsp90 $\beta$ (Fig. 6f,g).

Akt binds to amino acid residues $327-340$ of Hsp90ß. We speculated that PEDF might compete with Akt to bind with Hsp90 $\beta$ at the same site. To identify the binding site in Hsp90 $\beta$, deletion mutants of Hsp90 $\beta$ were constructed, as 
Fig. 8 PEDF downregulates peNOS by triggering the membrane translocation of Hsp90ß. (a) PEDF (green) and Hsp90 $\beta$ (red) immunostaining in HUVECs. (b) Streptavidin immunoblotting after immunoprecipitation (IP) for Hsp $90 \beta$ in lysates from HUVECs incubated with membraneimpermeant biotin and (c) PEDF immunoblotting after IP for Hsp $90 \beta$ in HUVEC membrane fractions. Expression of $\mathrm{Hsp} 90 \beta$ on the membrane was detected with immunostaining (d) and western blot (e-g) and in HUVECs treated with Ad-PEDF for $12 \mathrm{~h}$. (h) p-eNOS $\left(\operatorname{Ser}^{1177}\right)$, pAkt $\left(\mathrm{Thr}^{308}\right)$ levels and (i) IP for Akt or eNOS in HUVECs treated with the Hsp90 $\beta$ neutralisation antibody (Hsp90 $3-\mathrm{Ab}$ ) for $30 \mathrm{~min}$ and then exposed to rPEDF for $60 \mathrm{~min}$. Bars correspond to the mean $\pm \mathrm{SD}$, and experiments were replicated with three or more separate HUVEC samples. Images were acquired under a laser scanning confocal microscope; scale bars, $25 \mu \mathrm{m}$. $* p<0.05, * * p<0.01$ $* * * p<0.001$. Ctrl, control

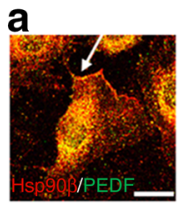

b
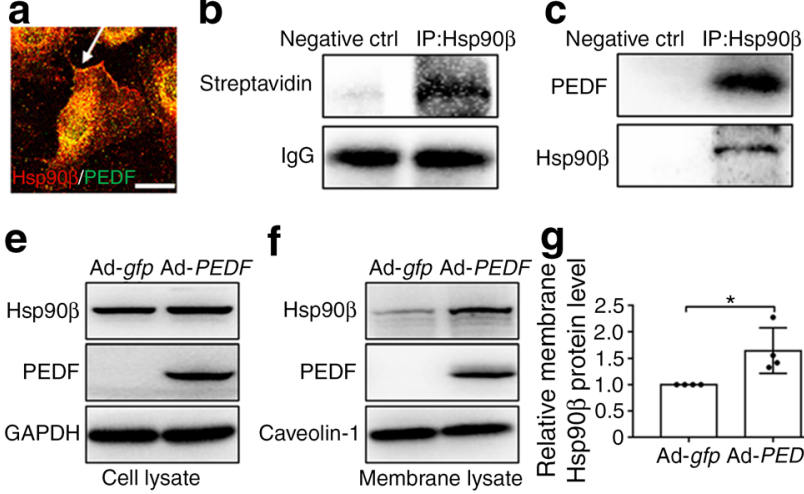

f
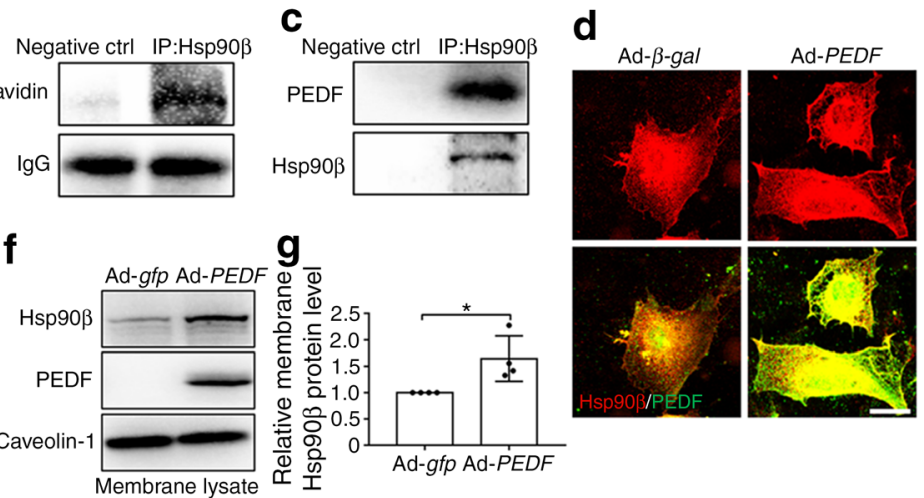

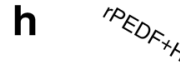

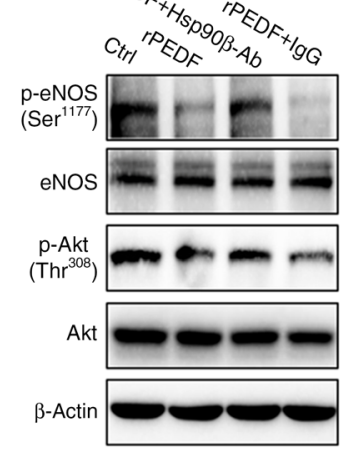

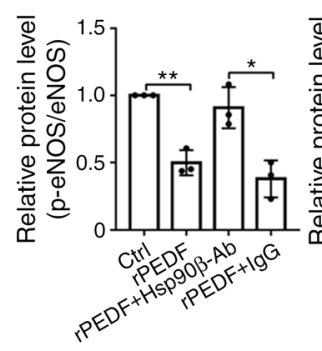

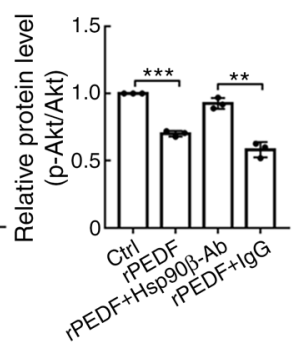

i
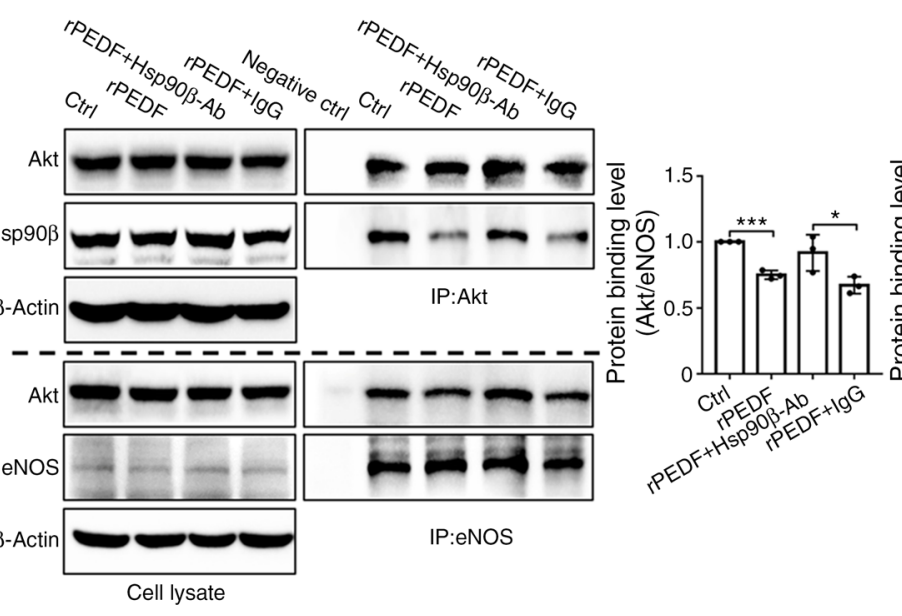

indicated in Fig. 7a. Unexpectedly, coimmunoprecipitation experiments showed that PEDF formed a complex with 341-724 truncated Hsp90 3 , which was not identical to the Akt binding site (Fig. 7b). These results indicated that no competition between PEDF and Akt for binding to Hsp90 $\beta$ exists. In this scenario, it is possible that the binding of PEDF with Hsp90 $\beta$ at residues 341-724 causes a conformational change and hinders Akt-Hsp90 $\beta$ binding.

It has been reported that Hsp90 $\beta$ is dimeric, and the Cterminal domain is the site of the obligatory dimerisation interface, only the Hsp90 $\beta$ dimer can normally function [31]. We found that the level of Hsp $90 \beta$ monomer was increased while the Hsp90 $\beta$ dimer was reduced in rPEDF- and Ad$P E D F$-treated cells (Fig. 7c). Based on these data, we propose a model in which PEDF decreases the dimerisation of $\mathrm{Hsp} 90 \beta$ by direct binding to amino acid residues $341-724$ of $\mathrm{Hsp} 90 \beta$ and abolishes the interaction of Akt with Hsp90ß/eNOS, subsequently inhibiting Akt/eNOS signalling (Fig. 7d).

\section{PEDF facilitates the membrane translocation of $\mathrm{Hsp} 90 \mathrm{\beta}$ and is} a candidate ligand of Hsp90 $\beta$ PEDF was elevated in the serum of diabetic participants, and Hsp90 $\beta$ was found at the cell surface membrane [32]. It is probable that PEDF interacts with the membrane-bound Hsp90 $\beta$. Our previous study demonstrated that PEDF triggers the translocation of Fas protein to the plasma membrane [33]. Thus, we first performed immunofluorescence staining with Hsp90 $\beta$ and PEDF and showed that they colocalised on the membrane (Fig. 8a). Next, we 
detected extracellular Hsp90 $\beta$ by cell-impermeant biotin labelling (Fig. 8b), and immunoprecipitation for $\mathrm{Hsp} 90 \beta$ in endothelial cell membrane fractions indicated that PEDF binds to Hsp90 $\beta$ on the membrane (Fig. 8c). Meanwhile, immunofluorescence staining showed that PEDF promoted the colocalisation with Hsp90 $\beta$ on the membrane (Fig. 8d) and decreased the dimerisation of membrane Hsp90 $\beta$ (ESM Fig. 12a). Furthermore, overexpression of PEDF increased membrane Hsp90ß levels, while total Hsp90ß was unchanged (Fig. 8e-g, ESM Fig. 12b). In addition, Hsp90ß$\mathrm{Ab}$ blocked the reduction in p-eNOS induced by PEDF (Fig. $8 \mathrm{~h}$ ), and the Akt/Hsp90ß/eNOS complex formation was rescued by the Hsp90ß-Ab in PEDF-treated cells (Fig. 8i). These data indicate that PEDF facilitates the membrane translocation of Hsp90 $\beta$ and downregulates p-eNOS through the Akt/Hsp90ß/eNOS complex.

\section{Discussion}

The treatment and management of erectile dysfunction in people with diabetes is more challenging than in nondiabetic individuals. Only $50 \%$ of people with DMED respond well to oral treatment with phosphodiesterase type 5 inhibitors (PDE5Is), which are currently the first-line therapy for treating erectile dysfunction [34]. It is acknowledged that PDE5Is improve and maintain the penile erection by inhibiting the degradation of cGMP, which is activated by NO [35]. Nevertheless, NO synthesis in endothelial cells is impaired in DMED and, thus, the therapeutic effect is restricted. Therefore, it is important to explore novel drug targets that could improve endothelial dysfunction and be used to treat DMED.

The present study revealed for the first time that PEDF levels were increased in human participants and diabetic animals with DMED compared with nondiabetic groups, and PEDF levels were negatively correlated with $\mathrm{NO}$ and IIEF-5 scores. Furthermore, gain- and loss-of-function experiments provide new evidence that a high level of PEDF plays a pathogenic role in DMED, which broadens our understanding of PEDF's pathophysiological function in diabetic complications. Of note, PEDF-Ab and PEDF deficiency ameliorate erectile function in animals with DMED at an early stage of diabetes but not at a late stage (ESM Fig. 13). These data indicate that early intervention with PEDF-Ab may be effective in ameliorating erectile function in diabetes patients who respond poorly to PDE5Is.

Endothelial injury is a crucial pathogenic factor in DMED, and the mechanism by which PEDF induces endothelial cell apoptosis has been extensively documented in our previous and other studies $[33,36]$. However, how PEDF mediates the synthesis of NO remains unknown. Neuronal NOS (or nNOS), cytokine-inducible NOS (iNOS), and endothelial NOS (eNOS) are NO synthase (NOS) isozymes that catalyse the production of NO from L-arginine. The studies on PEDF and iNOS are insufficient and contradictory, one showing that PEDF dampened iNOS expression [37], while another reported that PEDF stimulated iNOS in the prostate [38]. These confusing data might be due to differences in tissues or experimental conditions. NO liberated from nitrergic nerves contributes to the initiation of penile erection, and its maintenance is mediated by neurogenic and endothelial NO [39]. Any alteration in the formation of $\mathrm{NO}$ from the nerve terminals or the vascular endothelium could result in impaired corporal smooth muscle relaxation and the development of erectile dysfunction [40]. In the early stages of diabetes, nNOS expression is decreased in the nitrergic axons [41]. Diabetic men are prone to parasympathetic neuropathy, which might be a major contributor in DMED. In fact, nNOS (Nnos, also known as Nosl) knockout mice fail to achieve erections and are infertile as a consequence [42]. These studies suggest that $\mathrm{nNOS}$ plays an important role in both physical and diabetic penile erection. Thus, the regulation of nNOS by PEDF in erectile dysfunction is worthy of our further investigation.

Meanwhile, studies demonstrated that erectile dysfunction in diabetic men correlates with endothelial dysfunction [10-13]. In alloxan-induced diabetic rats, levels of eNOS in the sinusoidal and vascular endothelium decreased, and the eNOS effect apparently preceded the nNOS effect [43]. In addition, VEGF failed to increase erectile responses in intact Enos $^{-/-}$mice [44]. Moreover, eNOS mediates NO-dependent penile erection in $\mathrm{Nnos}^{-/}$animals and normal penile erection [45]. Furthermore, plasma nitrite in fasting human volunteers is mainly derived from eNOS [46], and we have shown that plasma nitrite was reduced and PEDF was elevated in the plasma of DMED patients. Therefore, we focus on the regulation of PEDF on cavernosum eNOS in DMED.

eNOS is localised in caveolae, in which caveolin-1 protein captures eNOS, resulting in the localisation of eNOS to caveolar microdomains. The dissociation from caveolin-1 facilitated the translocation of eNOS to the cytosol and enhanced the binding of eNOS with Hsp90 $\beta$ [47]. Thus, it is reasonable to assume that PEDF stimulated the binding of eNOS with caveolin-1, thus dampening the eNOS phosphorylation level. However, our data show that the caveolin-1 level was unchanged in cells treated with $\mathrm{rPEDF}$ and that high glucose had no effect on the binding of eNOS with caveolin-1 (ESM Fig. 14).

$\mathrm{PI} 3 \mathrm{~K} / \mathrm{Akt}$ is one of the central signalling pathways regulating the synthesis of NO by eNOS Ser ${ }^{617}$ and $\mathrm{Ser}^{1179}$ phosphorylation in endothelial cells [48]. It is known that $\operatorname{Ser}^{617}$, $\mathrm{Ser}^{635}$ and $\mathrm{Ser}^{1179}$ phosphorylation results in the activation of eNOS, the phosphorylation of $\mathrm{Ser}^{116}$ and $\mathrm{Thr}^{497}$ reduces eNOS function, and the phosphorylation of $\mathrm{Ser}^{1179}$ is common for multiple diverse signalling systems [49]. Our results, taken together, launch a new notion and provide new evidence that PEDF decreases eNOS Ser ${ }^{1179}$ phosphorylation levels by disrupting the Akt/Hsp90ß/eNOS complex. In addition, the 
other phosphorylation modification changes to eNOS by PEDF should be studied in the future.

The search for the PEDF receptor is still not very advanced, and LDL receptor-related protein 6 (LRP6), adipose triglyceride lipase (ATGL) and the laminin receptor (LR) have all been reported as receptors for PEDF [15, 50]. However, LRP6 mRNA and protein levels were hardly detectable in CCECs (data not shown), and ATGL is not directly involved in PEDF's antiangiogenic activity in endothelial cells [51]. In addition, knockdown of LR was unable to abolish the inhibitory effect of PEDF on p-Akt and p-eNOS (data not shown). This suggests that different receptors in various cell types mediate different cellular functions. In this study, we demonstrated for the first time the direct binding of PEDF with Hsp90 $\beta$ on the membrane, and that Hsp90 $\beta$-Ab blocks the effect of PEDF, which strongly indicates that $\mathrm{Hsp} 90 \mathrm{\beta}$ is a candidate receptor specific for PEDF regulating Akt/eNOS signalling in endothelial function. Meanwhile, we identified a new partner protein for Hsp90 $\beta$, and it is reasonable to suppose that PEDF could function in another signalling pathway that involves Hsp90 $\beta$ in other cells and is worthy of study.

In conclusion, these results indicate that elevated PEDF levels contribute to impaired erectile function by targeting the endothelium through Akt signalling, which is beneficial for improving the understanding of the pathophysiology of DMED. As shown in ESM Fig. 15, the blockage of PEDF in the early stages of diabetes represents a novel therapeutic target for the treatment of DMED.

Data and resource availability All data generated or analysed during this study are included in the published article (and its online supplementary files). No applicable resources were generated or analysed during the current study.

Funding This study was supported by the National Nature Science Foundation of China, grant numbers: 81770808, 81570871, 81872165, 81572342, 81471033, 81600641, 81370945, 81570764, 81701414, 81871211 and 81502507; National Key R\&D Program of China, grant numbers: 2018YFA0800403; Guangdong Provincial Key R\&D Program grant numbers: 2018B030337001, 2019B020227003; National Key SciTech Special Project of China, grant number: 2013ZX09102-053, 2015GKS-355; Key Project of Nature Science Foundation of Guangdong Province, China, grant number: 2015A030311043, 2016A030311035. Guangdong Natural Science Fund, grant number: 2014A020212023, 2014A030313073, 2015A030313029, 2015A030313103, 2019A1515011810; Guangdong Science Technology Project, grant number: 2017A020215075, 2015B090903063; Guangdong Special Support Fund: 201629046; Initiate Research Funds for the Central Universities of China (Youth Program), grant number: 14ykpy05, 16ykpy24. Key Sci-Tech Research Project of Guangzhou Municipality, China, grant number: 201508020033, 201510010052, 201707010084, 201803010017; Guangzhou Science and Technology Project, China, grant number: 201807010069; Pearl River Nova Program of Guangzhou Municipality, China, grant number: 201610010186; 2017 and 2019 Milstein Medical Asian American Partnership Foundation Research Project Award in Translational Medicine.

Authors' relationships and activities The authors declare that there are no relationships or activities that might bias, or be perceived to bias, their work.
Contribution statement TZ, GQG, XY, DC and ZZF conceived the study. LY, FPL and JPD oversaw patient recruitment and contributed to the clinical data and biological sample collection. DC and ZZF performed the experiments and finalised the dataset. JYX, JF, PY, WWQ, ZHY and JXM contributed to the data analysis and discussion. TZ, DC and ZZF drafted the manuscript and all authors revised and edited the manuscript. All authors read and approved the final manuscript. DC, ZZF, TZ, GQG and $\mathrm{XY}$ are the guarantors of this work taking responsibility for the integrity of the data and the accuracy of the data analysis.

\section{References}

1. National Institutes of Health (1993) Consensus development conference statement. Impotence. December 7-9, 1992. Int J Impot Res 5(4):181-284

2. Prieto D (2008) Physiological regulation of penile arteries and veins. Int J Impot Res 20(1):17-29. https://doi.org/10.1038/sj.ijir. 3901581

3. Shamloul R, Ghanem H (2013) Erectile dysfunction. Lancet 381(9861):153-165. https://doi.org/10.1016/S0140-6736(12) 60520-0

4. Jackson $\mathrm{G}$ (2007) The importance of risk factor reduction in erectile dysfunction. Curr Urol Rep 8(6):463-466. https://doi.org/10.1007/ s11934-007-0049-x

5. Wild S, Roglic G, Green A, Sicree R, King H (2004) Global prevalence of diabetes: estimates for the year 2000 and projections for 2030. Diabetes Care 27(5):1047-1053. https://doi.org/10.2337/ diacare.27.5.1047

6. Thorve VS, Kshirsagar AD, Vyawahare NS, Joshi VS, Ingale KG, Mohite RJ (2011) Diabetes-induced erectile dysfunction: epidemiology, pathophysiology and management. J Diabetes Complicat 25(2):129-136. https://doi.org/10.1016/j.jdiacomp.2010.03.003

7. Giugliano F, Maiorino M, Bellastella G, Gicchino M, Giugliano D, Esposito K (2010) Determinants of erectile dysfunction in type 2 diabetes. Int J Impot Res 22(3):204-209. https://doi.org/10.1038/ ijir.2010.1

8. Guay A, Jacobson J (2007) The relationship between testosterone levels, the metabolic syndrome (by two criteria), and insulin resistance in a population of men with organic erectile dysfunction. $\mathrm{J}$ Sex Med 4(4 Pt 1):1046-1055. https://doi.org/10.1111/j.17436109.2007.00530.x

9. Johannes CB, Araujo AB, Feldman HA, Derby CA, Kleinman KP, McKinlay JB (2000) Incidence of erectile dysfunction in men 40 to 69 years old: longitudinal results from the Massachusetts male aging study. J Urol 163(2):460-463

10. Castela A, Costa C (2016) Molecular mechanisms associated with diabetic endothelial-erectile dysfunction. Nat Rev Urol 13(5):266274. https://doi.org/10.1038/nrurol.2016.23

11. Behrendt D, Ganz P (2002) Endothelial function. From vascular biology to clinical applications. Am J Cardiol 90(10C):40L-48L. https://doi.org/10.1016/s0002-9149(02)02963-6

12. Maxwell AJ (2002) Mechanisms of dysfunction of the nitric oxide pathway in vascular diseases. Nitric Oxide 6(2):101-124. https:// doi.org/10.1006/niox.2001.0394

13. Costa C, Soares R, Castela A et al (2009) Increased endothelial apoptotic cell density in human diabetic erectile tissuecomparison with clinical data. J Sex Med 6(3):826-835. https:// doi.org/10.1111/j.1743-6109.2008.01110.x

14. Dawson DW, Volpert OV, Gillis P et al (1999) Pigment epitheliumderived factor: a potent inhibitor of angiogenesis. Science 285(5425):245-248. https://doi.org/10.1126/science.285.5425.245

15. Becerra SP, Notario V (2013) The effects of PEDF on cancer biology: mechanisms of action and therapeutic potential. Nat Rev Cancer 13(4):258-271. https://doi.org/10.1038/nrc3484 
16. Qi W, Yang C, Dai Z et al (2015) High levels of pigment epithelium-derived factor in diabetes impair wound healing through suppression of Wnt signaling. Diabetes 64(4):1407-1419. https://doi.org/10.2337/db14-1111

17. Wang P, Smit E, Brouwers MC et al (2008) Plasma pigment epithelium-derived factor is positively associated with obesity in Caucasian subjects, in particular with the visceral fat depot. Eur $\mathbf{J}$ Endocrinol 159(6):713-718. https://doi.org/10.1530/EJE-08-0521

18. Yamagishi S, Adachi H, Abe A et al (2006) Elevated serum levels of pigment epithelium-derived factor in the metabolic syndrome. $\mathrm{J}$ Clin Endocrinol Metab 91(6):2447-2450. https://doi.org/10.1210/ jc. 2005-2654

19. Jin HR, Kim WJ, Song JS et al (2009) Functional and morphologic characterizations of the diabetic mouse corpus cavernosum: comparison of a multiple low-dose and a single high-dose streptozotocin protocols. J Sex Med 6(12):3289-3304. https://doi. org/10.1111/j.1743-6109.2009.01464.x

20. Liu G, Sun X, Dai Y et al (2010) Chronic administration of sildenafil modified the impaired VEGF system and improved the erectile function in rats with diabetic erectile dysfunction. J Sex Med 7(12): 3868-3878. https://doi.org/10.1111/j.1743-6109.2010.01844.x

21. Dai Z, Qi W, Li C et al (2013) Dual regulation of adipose triglyceride lipase by pigment epithelium-derived factor: a novel mechanistic insight into progressive obesity. Mol Cell Endocrinol 377(12):123-134. https://doi.org/10.1016/j.mce.2013.07.001

22. Wang JJ, Zhang SX, Mott R et al (2006) Salutary effect of pigment epithelium-derived factor in diabetic nephropathy: evidence for antifibrogenic activities. Diabetes 55(6):1678-1685. https://doi. org/10.2337/db05-1448

23. Dall'Era JE, Meacham RB, Mills JN et al (2008) Vascular endothelial growth factor (VEGF) gene therapy using a nonviral gene delivery system improves erectile function in a diabetic rat model. Int $\mathrm{J}$ Impot Res 20(3):307-314. https://doi.org/10.1038/ijir.2008.1

24. Yin GN, Choi MJ, Kim WJ et al (2014) Inhibition of Ninjurin 1 restores erectile function through dual angiogenic and neurotrophic effects in the diabetic mouse. Proc Natl Acad Sci U S A 111(26): E2731-E2740. https://doi.org/10.1073/pnas.1403471111

25. Jaffe EA, Nachman RL, Becker CG, Minick CR (1973) Culture of human endothelial cells derived from umbilical veins. Identification by morphologic and immunologic criteria. J Clin Invest 52(11): 2745-2756. https://doi.org/10.1172/JCI107470

26. Zhou T, Che D, Lan Y et al (2017) Mesenchymal marker expression is elevated in Muller cells exposed to high glucose and in animal models of diabetic retinopathy. Oncotarget 8(3):4582-4594. https:// doi.org/10.18632/oncotarget.13945

27. Kodama Y, Hu CD (2010) An improved bimolecular fluorescence complementation assay with a high signal-to-noise ratio. BioTechniques 49(5):793-805. https://doi.org/10.2144/000113519

28. Li L, Yao YC, Gu XQ et al (2014) Plasminogen kringle 5 induces endothelial cell apoptosis by triggering a voltage-dependent anion channel 1 (VDAC1) positive feedback loop. J Biol Chem 289(47): 32628-32638. https://doi.org/10.1074/jbc.M114.567792

29. Sheikpranbabu S, Haribalaganesh R, Banumathi E, Sirishkumar N, Lee KJ, Gurunathan S (2009) Pigment epithelium-derived factor inhibits advanced glycation end-product-induced angiogenesis and stimulates apoptosis in retinal endothelial cells. Life Sci 85(21-22):719-731. https://doi.org/10.1016/j.lfs.2009.09.015

30. Haribalaganesh R, Sheikpranbabu S, Elayappan B, Venkataraman D, Gurunathan S (2009) Pigment-epithelium-derived factor down regulates hyperglycemia-induced apoptosis via PI3K/Akt activation in goat retinal pericytes. Angiogenesis 12(4):381-389. https://doi. org/10.1007/s10456-009-9159-Z

31. Meyer P, Prodromou C, Hu B et al (2003) Structural and functional analysis of the middle segment of hsp90: implications for ATP hydrolysis and client protein and cochaperone interactions. Mol
Cell 11(3):647-658. https://doi.org/10.1016/s1097-2765(03) 00065-0

32. Snigireva AV, Vrublevskaya VV, Afanasyev VN, Morenkov OS (2015) Cell surface heparan sulfate proteoglycans are involved in the binding of Hsp90 $\alpha$ and Hsp90 $\beta$ to the cell plasma membrane. Cell Adhes Migr 9(6):460-468. https://doi.org/10.1080/19336918. 2015.1103421

33. Li L, Yao YC, Fang SH et al (2014) Pigment epithelial-derived factor (PEDF)-triggered lung cancer cell apoptosis relies on p53 protein-driven Fas ligand (Fas-L) up-regulation and Fas protein cell surface translocation. J Biol Chem 289(44):30785-30799. https:// doi.org/10.1074/jbc.M114.590000

34. Vickers MA, Satyanarayana R (2002) Phosphodiesterase type 5 inhibitors for the treatment of erectile dysfunction in patients with diabetes mellitus. Int J Impot Res 14(6):466-471. https://doi.org/ 10.1038/sj.ijir.3900910

35. Carson CC, Lue TF (2005) Phosphodiesterase type 5 inhibitors for erectile dysfunction. BJU Int 96(3):257-280. https://doi.org/10. 1111/j.1464-410X.2005.05614.x

36. Zhang H, Wei T, Jiang $X$ et al (2016) PEDF and 34-mer inhibit angiogenesis in the heart by inducing tip cells apoptosis via upregulating PPAR- $\gamma$ to increase surface FasL. Apoptosis 21(1):60 68. https://doi.org/10.1007/s10495-015-1186-1

37. Zhang SX, Wang JJ, Dashti A et al (2008) Pigment epitheliumderived factor mitigates inflammation and oxidative stress in retinal pericytes exposed to oxidized low-density lipoprotein. J Mol Endocrinol 41(3):135-143. https://doi.org/10.1677/JME-08-0011

38. Nelius T, Samathanam C, Martinez-Marin D et al (2013) Positive correlation between PEDF expression levels and macrophage density in the human prostate. Prostate 73(5):549-561. https://doi. org/10.1002/pros. 22595

39. Toda N, Toda H (2010) Nitric oxide-mediated blood flow regulation as affected by smoking and nicotine. Eur J Pharmacol 649(13):1-13. https://doi.org/10.1016/j.ejphar.2010.09.042

40. Bivalacqua TJ, Usta MF, Champion HC, Kadowitz PJ, Hellstrom WJ (2003) Endothelial dysfunction in erectile dysfunction: role of the endothelium in erectile physiology and disease. J Androl 24(6 Suppl):S17-S37. https://doi.org/10.1002/j.1939-4640.2003. tb02743.x

41. Cellek S (2004) Point of NO return for nitrergic nerves in diabetes: a new insight into diabetic complications. Curr Pharm Des 10(29): 3683-3695. https://doi.org/10.2174/1381612043382792

42. Gyurko R, Leupen S, Huang PL (2002) Deletion of exon 6 of the neuronal nitric oxide synthase gene in mice results in hypogonadism and infertility. Endocrinology 143(7):2767-2774. https://doi.org/10.1210/endo.143.7.8921

43. Akingba AG, Burnett AL (2001) Endothelial nitric oxide synthase protein expression, localization, and activity in the penis of the alloxan-induced diabetic rat. Mol Urol 5(4):189-197. https://doi. org/10.1089/10915360152745885

44. Musicki B, Palese MA, Crone JK, Burnett AL (2004) Phosphorylated endothelial nitric oxide synthase mediates vascular endothelial growth factor-induced penile erection. Biol Reprod 70(2):282-289. https://doi.org/10.1095/biolreprod.103.021113

45. Burnett AL, Nelson RJ, Calvin DC et al (1996) Nitric oxidedependent penile erection in mice lacking neuronal nitric oxide synthase. Mol Med 2(3):288-296

46. Kim-Shapiro DB, Gladwin MT (2015) Pitfalls in measuring NO bioavailability using NOx. Nitric Oxide 44:1-2. https://doi.org/10. 1016/j.niox.2014.10.003

47. Vanhoutte PM, Zhao Y, Xu A, Leung SW (2016) Thirty years of saying NO: sources, fate, actions, and misfortunes of the endothelium-derived vasodilator mediator. Circ Res 119(2):375396. https://doi.org/10.1161/CIRCRESAHA.116.306531

48. Cross DA, Alessi DR, Cohen P, Andjelkovich M, Hemmings BA (1995) Inhibition of glycogen synthase kinase-3 by insulin 
mediated by protein kinase B. Nature 378(6559):785-789. https:// doi.org/10.1038/378785a0

49. Kolluru GK, Siamwala JH, Chatterjee S (2010) eNOS phosphorylation in health and disease. Biochimie 92(9):1186-1198. https:// doi.org/10.1016/j.biochi.2010.03.020

50. Park K, Lee K, Zhang B et al (2011) Identification of a novel inhibitor of the canonical Wnt pathway. Mol Cell Biol 31(14): 3038-3051. https://doi.org/10.1128/MCB.01211-10
51. He X, Cheng R, Benyajati S, Ma JX (2015) PEDF and its roles in physiological and pathological conditions: implication in diabetic and hypoxia-induced angiogenic diseases. Clin Sci (Lond) 128(11): 805-823. https://doi.org/10.1042/CS20130463

Publisher's note Springer Nature remains neutral with regard to jurisdictional claims in published maps and institutional affiliations. 